\title{
Ultra-nano indentation properties of crosslinked PBT
}

\author{
Martin Ovsik ${ }^{1, *}$, Tomas Fiala ${ }^{1}$, Miroslav Manas ${ }^{1}$, and Adam Dockal ${ }^{1}$ \\ ${ }^{1}$ Tomas Bata University in Zlin, TGM 5555, 76001 Zlin, Czech Republic
}

\begin{abstract}
This article deals with the use of Ultra-nano indentation Tester $\mathrm{UNHT}^{3}$ for the measurement of (ultra nano) mechanical properties. The effect of electron beam (EB) radiation on Polybutylene terephthalate (PBT) was investigated. To clarify whether crosslinking could take place without or only with the presence of a crosslinking agent, special attention was paid to the incorporation of this agent into tested polymer. In this study we have investigated the effect of crosslinking agent, and instantaneously electron beam radiation-induced crosslinking in the presence of Triallyl cyanurate on various mechanical properties of PBT. The results show that the influence of radiation has improved the observed properties in the surface layer. The increase in ultra-nano properties was around $26 \%$ over the basic material. Engineering plastics like Poly (butylene terephthalate) due to their desirable properties have various industrial applications.
\end{abstract}

\section{Introduction}

Polybutylene Terephthalate (PBT) is a semi-crystalline engineering thermoplastic material. It has similar properties and composition to polyethylene terephthalate (PET). It is a member of polyester family of polymers. PBT is produced by polycondensation of terephthalic acid or dimethyl terephthalate with 1,4-butanediol using special catalysts (Figure 1). [1] [2]

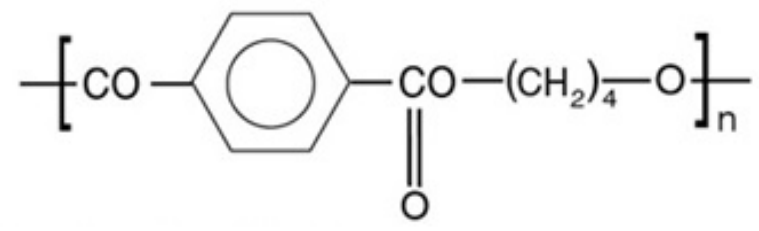

Fig. 1. Molecular Structure of Polybutylene Terephthalate. [1]

Polybutylene terephthalate has gained commercial interest due to its wide range of applications ranging from automotive, electrical and electronics, medical and many more. Properties of PBT: [3-5]

- It delivers excellent short-term mechanical properties, such as high strength, toughness and stiffness as well as good practical impact.

- It provides good creep resistance, dimensional stability and low moisture absorption characteristics.

- It gives good durability under thermal stress and harsh chemical environments, particularly in automotive underhood applications.

E-beam crosslinking is a powerful tool used to improve the properties of a wide range of polymers in the creation of value-added specialty products. The crosslinking of polymers through electron-beam processing changes a thermoplastic material into a thermoset. [6][7] When polymers are crosslinked, the molecular movement is severely impeded, making the polymer stable against heat. Crosslinking is the interconnection of adjacent long molecules with networks of bonds induced by chemical treatment or electron-beam treatment. This locking together of molecules is the origin of all of the benefits of crosslinking, including the improvement of the following properties: [8]

- Thermal: resistance to temperature, aging, lowtemperature impact, etc.

- Mechanical: tensile strength, modulus, abrasion resistance, pressure rating, creep resistance, etc.

- Chemical: stress crack resistance, etc.

- Other: heat shrink memory properties, positive temperature coefficient, etc.

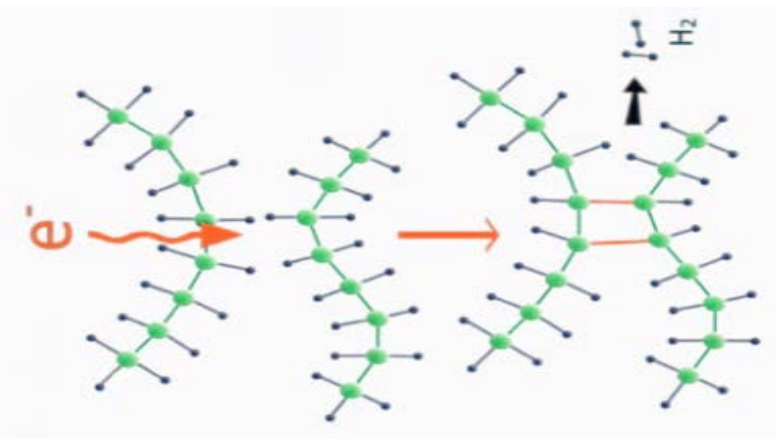

Fig. 2. Crosslinking process. [8]

The present work deals with the influence of ultranano indentation properties of irradiated crosslinked PBT. The aim of this paper is to study the effect of ionizing radiation with beta irradiation, on mechanical properties of surface layer of polybutylene terephthalate (PBT) and compare these results with those of nonirradiated samples.

* Corresponding author: ovsik@utb.cz

(C) The Authors, published by EDP Sciences. This is an open access article distributed under the terms of the Creative Commons Attribution 


\section{Experimental}

\subsection{Material}

For this experiment Polybutylene terephthalate (PBT) VPTS-CREATECB3HZC * M800/25 nature (PTS Plastics Technologie Service, Germany) was used. The material already contained the special crosslinking agent TAIC triallyl isocyanurate (6 volume \%), which should enable subsequent crosslinking by ionizing $\beta$ - radiation.

\subsection{Sample preparation}

The samples were made using injection molding technology on an Arburg Allrounder $470 \mathrm{H}$ injection molding machine (Loßburg, Germany). The normalized specimens, with dimensions of $(80 \times 10 \times 4) \mathrm{mm}$, were used (Figure 3). The process parameters were set according to the manufacturer's recommendations; see Table 1.

Table 1. Process parameters.

\begin{tabular}{ccc}
\hline Parameters & Unit & PBT \\
\hline Injection Pressure & $\mathrm{MPa}$ & 70 \\
Cooling Time & $\mathrm{s}$ & 20 \\
Mould Temperature & ${ }^{\circ} \mathrm{C}$ & 60 \\
Zone 1 & ${ }^{\circ} \mathrm{C}$ & 250 \\
Zone 2 & ${ }^{\circ} \mathrm{C}$ & 260 \\
Zone 3 & ${ }^{\circ} \mathrm{C}$ & 270 \\
Zone 4 & ${ }^{\circ} \mathrm{C}$ & 280 \\
\hline
\end{tabular}

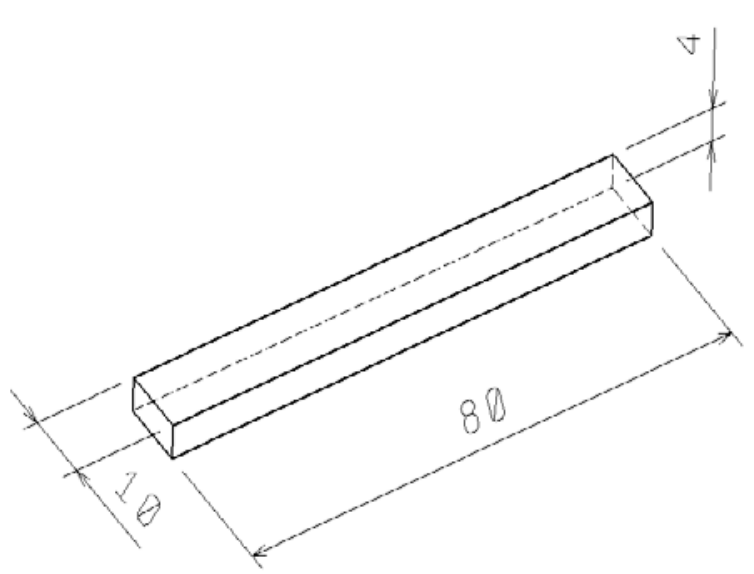

Fig. 3. Dimension of sample.

\subsection{Irradiation process}

The crosslinking causes the connection of polymeric chains to each other, most often using covalent bonds to form the spatial network. Test bodies were irradiated under industrial conditions on a commercially available irradiation device in a broader range of radiation doses $(0,33,66$ and $99 \mathrm{kGy})$ compared to the doses corresponding to the experience in the practice.
All samples were irradiated with electron (beta) rays (accelerated electrons - A Rhodotron R E-beam accelerator, electron energy $10 \mathrm{MeV}$ ) in the firm BGS Beta Gamma Service GmbH \& Co, Saal am Danau Germany.

\subsection{Ultra-nano indentation test}

Ultra-nano indentation tests were performed using a special technics ultra-nano indentation tester $\mathrm{UNHT}^{3}$ (Figure 4), made by Anton Paar (Graz, Austria), according to the CSN EN ISO 14577 standard. The measurement was carried out using the depth sensing indentation (DSI) method. This method enables one to measure the force acting on the indentor, as well as the displacement of the indentor's tip. The tip is made of diamond and its shape is that of a cube corner (Vickers).

The measurement parameters are shown in Table 2. In Table 3 the Ultra Nanoindentation Tester - UNHT ${ }^{3}$ is technically specified.

Table 2. Measurement parameters.

\begin{tabular}{ccc}
\hline Parameters & Unit & Value \\
\hline Maximum Load & $\mathrm{uN}$ & 500 \\
Load/Unload Speed & $\mathrm{uN} / \mathrm{min}$ & 1000 \\
Holding Time & $\mathrm{s}$ & 90 \\
\hline
\end{tabular}

Table 3. Technically specified.

\begin{tabular}{ccc}
\hline Parameters & Unit & Value \\
\hline Force & $\mathrm{mN}$ & $0.01-100$ \\
Resolution & $\mathrm{nN}$ & 3 \\
Depth & $\mathrm{um}$ & 100 \\
Resolution & $\mathrm{nm}$ & 0.003 \\
& & ISO 14577, ASTM \\
International standards & & E2546 \\
\hline
\end{tabular}

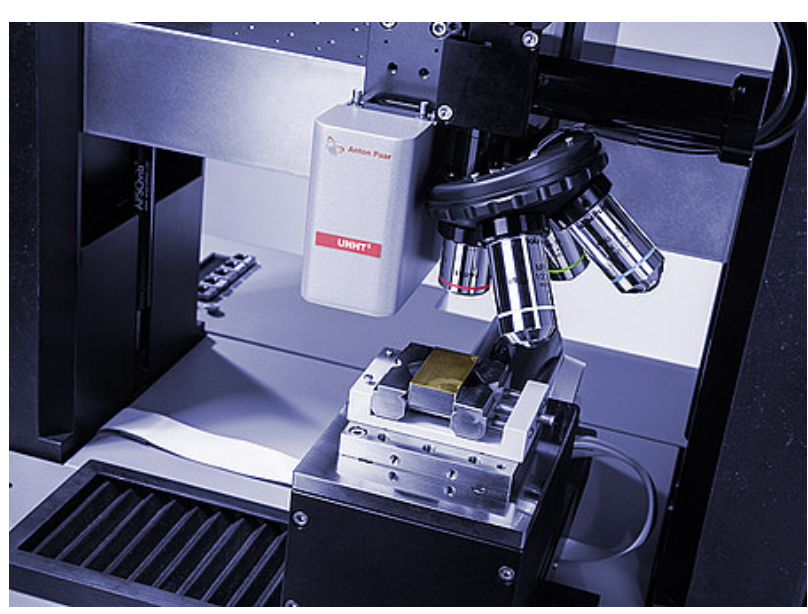

Fig. 4. Ultra-nano indentation Tester UNHT ${ }^{3}$.

The indentation hardness $\left(\mathrm{H}_{\mathrm{IT}}\right)$ was calculated as maximum load $\left(\mathrm{F}_{\max }\right)$ to the projected area of the hardness impression $\left(\mathrm{A}_{\mathrm{p}}\right)$ and the indentation modulus $\left(\mathrm{E}_{\mathrm{IT}}\right)$ is calculated from the Plane Strain modulus $\left(\mathrm{E}^{*}\right)$ 
using an estimated sample Poisson's ratio (v) according to [9-12]:

$$
\begin{gathered}
H_{I T}=\frac{F_{\max }}{A_{p}} \\
E_{I T}=E * \cdot\left(1-v_{s}{ }^{2}\right)
\end{gathered}
$$

Elastic and plastic part of the indentation work (figure $5)$ :

$$
\begin{aligned}
& \eta_{I T}=\frac{W_{\text {elast }}}{W_{\text {total }}} \cdot 100 \\
& W_{\text {total }}=W_{\text {elast }}+W_{\text {plast }}
\end{aligned}
$$

Plastic part $W_{\text {plast }} / W_{\text {total }}$ follows as $100 \%-\eta I T$

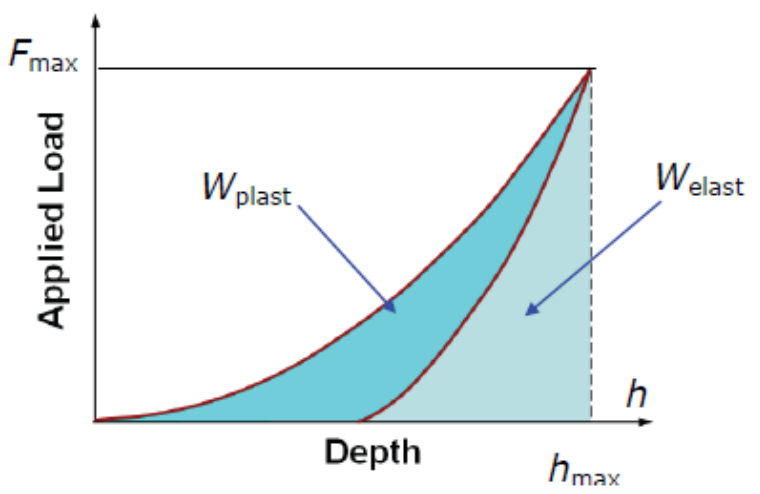

Fig. 5. Indentation work

Measurement of all above mentioned properties was performed 10 times to ensure statistical correctness.

\section{Results and discussion}

In Figures 6 and 7, indentation characteristics which are the basic measurement output are shown. From these dependencies the mechanical properties characterizing the surface of the test material are calculated. The test surface depth is $600 \mathrm{~nm}$ as shown in Figures 6 and 7.

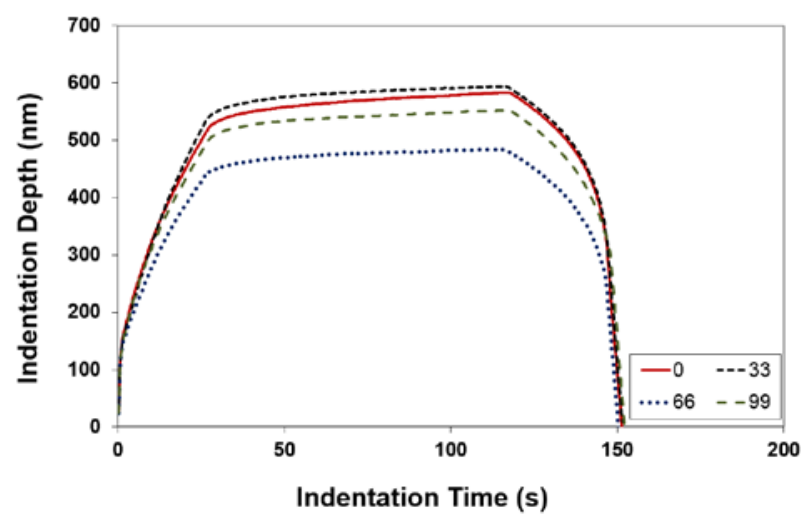

Fig. 6. Indentation characteristic
Figure 6 shows the dependence of the indentation depth on the indentation time. From this dependence, it is possible to determine creep properties of the tested material. Figure 7 shows the dependence of the indentation load on the indentation depth. Mechanical properties such as hardness, modulus, deformation work, etc. were calculated from this dependence, etc. Thanks to these indentation curves, it is possible to assess the behaviour of the material and its surface properties.

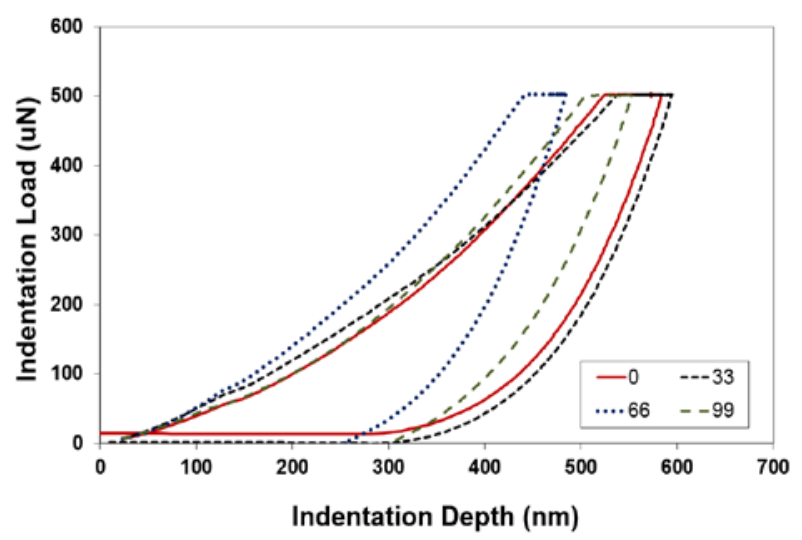

Fig. 7. Indentation characteristic

The measured values of the ultra-nano indentation test were obtained for PBT irradiated with beta rays as shown in Table 4.

Table 4. Ultra-nano indentation values

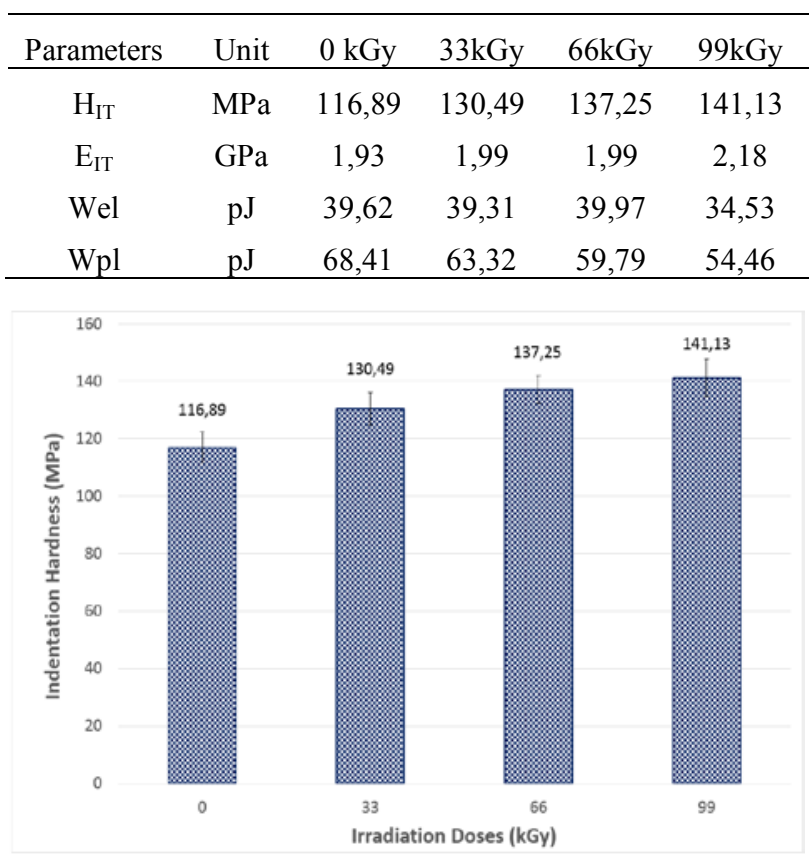

Fig. 8. Indentation hardness vs. Irradiation doses

From the results of the ultra-nano indentation test it is clear that irradiation has a positive effect on the indentation hardness of the surface layer of the tested PBT. The non-irradiated material exhibited an indentation hardness of approximately $117 \mathrm{MPa}$, while the highest hardness value was measured for PBT irradiated at the dose of $99 \mathrm{kGy}$, where the indentation hardness was $141 \mathrm{MPa}$. This performance improvement 
was up to $21 \%$, bringing PBT to the area of materials with better properties (Figure 8).

An important feature for assessing the mechanical properties of the surface of the component is the stiffness of the surface layer, which is characterized by the indentation modulus, as can be seen at Figure 9. This modulus corresponds to the modulus of elasticity obtained from the tensile test. Again, the base material showed the value of the indentation modulus $1.9 \mathrm{GPa}$. The highest improvement in the properties was due to irradiation of the tested PBT at a dose of $99 \mathrm{kGy}$, where the indentation modulus was $2.2 \mathrm{GPa}$. The increase of the indentation modulus was $13 \%$.

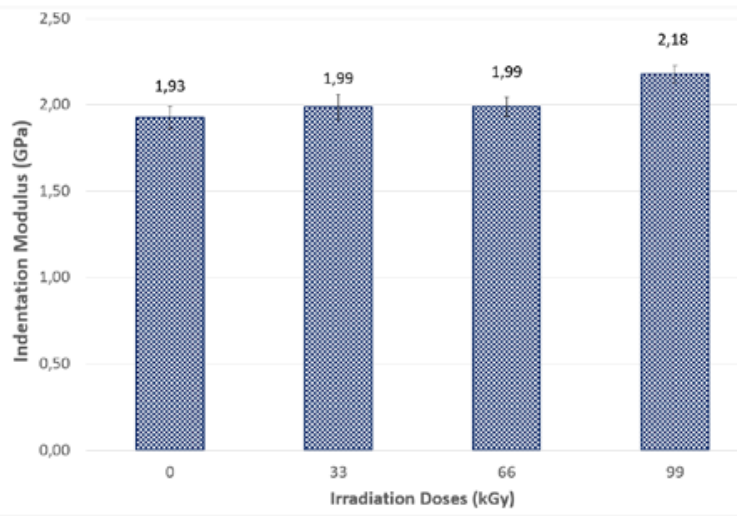

Fig. 9. Indentation modulus vs. Irradiation doses

To assess the properties of the surface layer is an important parameter of the deformation work, which describes the elastic and plastic part of the material (Figure 10.). The non-irradiated material showed a value of $68 \mathrm{pJ}$ of plastic work and the elastic part of the work was $40 \mathrm{pJ}$. With the dose of radiation there was a decrease in both components of the deformation work. The plastic work was $54 \mathrm{pJ}$ and the elastic work was 35 pJ. The difference in the decrease of both works was $26 \%$.

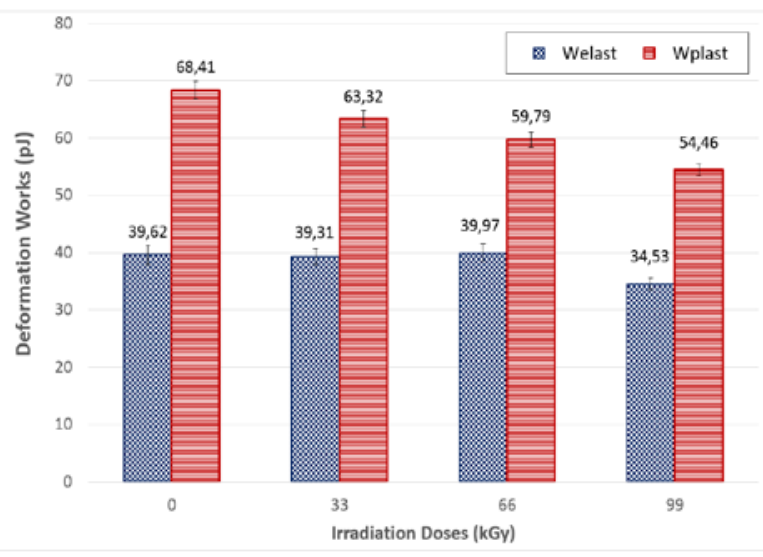

Fig. 10. Indentation works vs. Irradiation doses

\section{Conclusions}

The Ultra-Nano indentation Tester - $\mathrm{UNHT}^{3}$ was used to measure the mechanical properties of the surface layer.
The measurement was performed at non-irradiated and irradiated PBT (radiation doses 33, 66 and $99 \mathrm{kGy}$ ).

From the measurement results, it is evident that radiation crosslinking has a positive effect on the mechanical properties (ultra-nano):

- Increase of the indentation and Vickers hardness by up to $21 \%$ compared to the basic and irradiated material $(99 \mathrm{kGy})$

- Improved surface stiffness by $13 \%$ when compared to non-irradiated and irradiated PBT

- Improvement of the plastic and elastic part of the deformation work

As can be seen from the results, thanks to the betabeam crosslinking, it is possible to improve the mechanical properties of tested materials and thus to move the material into more expensive structural materials.

This work was supported by the European Regional Development Fund under the project CEBIA-Tech Instrumentation No. CZ.1.05/2.1.00/19.0376 and by the Ministry of Education, Youth and Sports of the Czech Republic within the National Sustainability Program project no. LO1303 (MSMT-7778/2014). Moreover, it was supported by the Internal Grant Agency of TBU in Zlin: no. IGA/FT/2018/012.

\section{References}

1. Drobny J.G., Radiation Technology for Polymers (CRC Press, New York, 2003)

2. Zhil Hooshangi, Seyed Amir Hossein Feghhi, Nasrin Sheikh, Radiation Physics and Chemistry 108, (2015)

3. T. Metanawin, A. Jamjumrus, S. Metanawin, Morphology, MATEC Web of Conferences 30, (2015)

4. M. Ovsik, L. Hylova, D. Manas, M. Manas, M. Stanek, MATEC Web of Conferences 76, (2016)

5. M. El Fray, G. Przybytniak, M.PiątekHnat, E.M. Kornacka, Polymer 51, (2010)

6. A. Barlow, et al. Radiat. Phys. Chem. 14, (2015)

7. J. Berejka Anthony, Daniel Montoney, R. Marshall, Loïc Loiseau, NUKLEONIKA. Institute of Nuclear Chemistry and Technology 55, (2010)

8. R. J. Woods, A. K. Picaev, Applied radiation chemistry: radiation processing (New York: John Wiley, 1994 ) 
9. D. Manas, M. Ovsik, A. Mizera, M. Manas, L. Hylova, M. Bednarik, M. Stanek, Polymers 10, 2 (2018)

10.M. Ovsik, M. Stanek, M. Reznicek, MATEC Web of Conferences 125, (2017)

11. W.C. Oliver, G.M. Pharr, J. Mater. Res., 19. (2004)

12. M. Stanek, M. Ovsik, D. Manas, M. Reznicek, WSEAS Transactions on Applied and Theoretical Mechanics 12, (2017) 